\title{
GÉNERO Y VIRTUALIDAD: Un tratado para la trascendencia
}

\author{
GENDER AND VIRTUALITY: \\ A treaty for trascendence
}

Juan Jesús Güere Porras ${ }^{1}$

\section{RESUMEN}

Se explica la dinámica de la ética en relación con el género y esta última en relación con la virtualidad. Todo ello, en el marco del tránsito hacia la virtualización de las mismas. Además, se aborda la problemática pública y privada en torno al género y a una ética de pluralidad de voces. Finalmente, se desarrolla la propuesta de virtualizar y realidizar el género, desde tecnologías como las redes sociales, blogs, App's, mundos virtuales, entre otras.

Palabras clave: Dinámica, género, virtualidad.

\section{ABSTRACT}

It explains the dynamics of ethics in relation to gender and the latter in relation to virtuality. All this, in the framework of the transition towards their virtualization. In addition, it addresses the public and private issues around gender and an ethic of plurality of voices. Finally, it is developed the proposal of virtualizing and realizing the genre, from technologies such as social networks, blogs, App's, virtual worlds, among others.

Keywords: Dynamics, gender, virtuality.

\section{INTRODUCCIÓN}

Se explica las igualdades y diferencias desde una ética atenta a la pluralidad de voces. Perspectiva que permite dilucidar la crítica sobre la dicotomía de lo público y privado, para canalizar la idea del género y de la ética desde el papel del otro generalizado y el otro concreto. Finalmente, se expone la propuesta a la problemática del género en relación a su construcción desde lo virtual.

Desde las preguntas del ¿cómo, dónde, cuándo, por qué y para qué somos lo que somos? hasta los sutiles avances en termodinámica, biotecnología, inteligencia artificial y simulación virtual. Desde los estudios sobre las tecnologías holográficas, hasta los últimos logros en autorrealización personal, hemos recorrido el camino del auto conocimiento, del ser y la existencia. Este proceso gradual ha desarrollado nuevas y novedosas formas de entender la ética y el género, para producir conocimientos que desarrollen sociedades más humanas e igualitarias.

Sin embargo, habría que preguntarnos, como lo hace Patrón (2007) sobre: ¿Qué tiene que ver la ética con el género? ¿La ética es diferente para las mujeres y los varones? ¿Se trata de paradigmas diferentes? ¿Opuestos? ¿Complementarios? ¿Qué es el género? ¿Cómo se construye el género desde lo virtual? ¿Cómo se virtualiza y realidiza el género? Este apetito académico será prontamente desarrollado en el presente estudio.

Butler (2007), afirma: "Además, el género propio no se «hace» en soledad. Siempre se está «haciendo» con o para otro, aunque el otro sea sólo imaginario. Lo que se llama mí "propio» género quizá aparece en ocasiones como algo que uno mismo crea o que, efectivamente, le pertenece".

\footnotetext{
${ }^{1}$ Investigador independiente. Universidad Nacional del Centro del Perú. Fundación Internacional para la Investigación, Arte, Cultura y Desarrollo “Yachay”. E-mail: jguereporras@gmail.com

Presentado: 01/02/17 Aprobado: 06/06/17
} 
Heiddegger (1947), "Ahora bien, lo que ante todo "es", es el ser. El pensar lleva a cabo la relación del ser con la esencia humana, este ofrecimiento consiste en el pensar del llegar a ser".

\section{Iguales y diferentes, una ética atenta a la plura- lidad de voces}

"Nunca en mi vida he 'amado' a ningún pueblo ni colectivo, ni al pueblo alemán, ni al francés, ni al norteamericano, ni a la clase obrera, ni a nada semejante. En efecto, sólo 'amo' a mis amigos y el único género de amor que conozco y en el que creo es el amor a las personas".

Hannah Arendt

El género del latín genus, hace referencia a una clase 0 conjunto de determinadas características, que abarca muchas áreas y disciplinas. Empero, en relación a la sexualidad, es un fenómeno que se constituye socioculturalmente, ya que se hace y desarrolla en torno a las relaciones sociales de un determinado ser frente a otro. Se halla afuera del mismo y va más allá de uno mismo, es una socialidad que no tiene un solo autor, una sola mirada, una solitaria perspectiva.

Se ha escrito en general del hombre como representando a toda la humanidad, lo cual supuestamente incluye a las mujeres. Al hablar de ética occidental del varón como siendo lo universal, la especificidad de la mujer, de lo femenino, ha sido históricamente dejado de lado. Por género entendemoss, siguiendo a Seyla Benhabib, a la construcción simbólica e interpretación sociohistórica de las diferencias anatómicas entre los sexos.

Paradigmas éticos que, comienzan con la filosofía occidental en el mundo griego. En tiempos modernos, del surgimiento del individuo autónomo y una razón igual para todos, las mujeres no se encuentran, ni en la discusión ética ni política. Esto se enraíza por las posturas de Hobbes, el mismo que no concibió a las mujeres como individuos, sino más bien motín de guerra. Es cierto que los hombres también pueden ser motín, pero en tanto han peleado una guerra y la han perdido, no porque son esposos de alguien.

Patrón (2007) refiriéndose a Locke, manifiesta que este, fundador del pensamiento democrático-liberal, fuente de inspiración de la Constitución de los Estados Unidos de Norteamérica, afirmaba la subordinación natural de las mujeres. Por otro lado, citando a Kant, recuerda que para el "las mujeres evitarían el mal, no por injusto, sino por feo y actos virtuosos son para ellas los normalmente bellos”. Es así que desde las raíces filosóficas occidentales, "la mujer es insoportable a todo orden, hacen algo porque les agrada y el arte residiría en hacer que les agrade aquello que es bueno".

Mientras que Hegel, en relación a la familia, refería que "las mujeres tienen tres relaciones distintas en la familia: como esposa; que se relaciona con el marido, como madre; que se relaciona con sus hijos y como hermana; que se relaciona con su hermano; representando así, la mujer, a la ironía de la comunidad”. Estas afirmaciones, reducen las dimensiones de la mujer a meros mecanicismos y determinaciones utilitaristas, olvidando el papel histórico de la mujer en la transformación de las sociedades en su conjunto.

Es así, que vivimos en una época atenta a las diferencias. En el Perú, del total de analfabetos que existen, el 75\% son mujeres, el $85 \%$ de los hogares encabezados por mujeres son pobres; el $87 \%$ de las víctimas de la violencia familiar, son mujeres. Estas mujeres son referidas como "mujeres desaparecidas". En el mundo ya hay una cantidad de 100 millones de mujeres desaparecidas, entre ellas 36 millones en la India.

En un mundo, cuyo sistema imperante es el de la mercancía y el capital, el poder sigue siendo masculino -en términos sociales, culturales y valorativos- y la pobreza sigue siendo mayoritariamente femenina, la construcción socio cultural de la ética y política sigue siendo fundamentalmente algo de los hombres. "Una mujer pública es todavía una ramera, un hombre político es el hombre que interviene públicamente en los negocios políticos" (Patrón, 2007).

Sin embargo, huelga sostener, que hombres y mujeres, somos como dijera Einstein "igualmente sabios e igualmente importantes". Para ello, las sociedades contemporáneas en la actualidad tienen que deshacerse de dos mentiras fundamentales, que son postuladas por Guilligan, primero; sobre la representación del hombre sobre toda la humanidad y segundo; sobre el desarrollo moral de las mujeres en el que se alternan algunas falsas voces feministas. No se trata, entonces, de oposición o exclusión, sino de iniciar una nueva forma de interacción ética en la que todas las voces puedan ser escuchadas, desde su complejidad y diversidad.

\section{Críticas feministas a la dicotomía públicay privada}

"La humanidad necesita hombres prácticos, que sacar el mayor provecho de su trabajo, y, sin olvidar el interés general, salvaguardar sus propios intereses. Pero la humanidad también necesita soñadores y soñadoras, para quienes el desarrollo de 
una tarea sea tan cautivante que les resulte imposible dedicar su atención a su propio beneficio colectivo"

Marie Curie

"Sois todavía jóvenes para ocuparos de política, no permitáis que nadie influya en vosotros", en el fondo dice: "no permitáis que nadie influya en vosotros, excepto yo y mi partido"

Madezhda Krupskaya

La contradicción entre lo privado y lo público, ha ocupado históricamente un papel central en la discusión política feminista. Por un lado, tenemos a la crítica feminista, entendida como la separación y la oposición entre las esferas pública y privada en la teoría y la práctica liberal. Por lo que, la relación entre el feminismo y el liberalismo es sumamente estrecha, pero también esencialmente compleja.

Mientras que el liberalismo es esencialmente ambiguo y vacío en cuanto a lo público y privado. Es así que, entre el feminismo y el liberalismo, hay una discrepancia sobre el dónde y porqué se debe trazar la distinción entre las dos esferas, es decir; entre lo público y lo privado. Sin embargo, la reivindicación a favor de la igualdad de los derechos humanos, siempre ha sido bandera y parte importante del feminismo como tal.

El feminismo va más allá del feminismo liberal. Unas feministas rechazan las posturas liberales entorno a lo privado y público y consideran que la estructura política es el principal factor que encumbre la desigualdad social y económica. Las feministas, en su mayoría, plantean el problema, generalmente olvidado del carácter patriarcal del liberalismo.

El carácter patriarcal del liberalismo tiene que ver con las coincidencias de Locke y Filmer sobre la utilidad de la mujer, mencionando lo siguiente: "la subordinación de la esposa a su marido se basa en la naturaleza, así como en la voluntad del marido prevaleciente en el hogar, como ser más capaz y fuerte". La participación, entonces, en la esfera pública se rige por criterios de éxito, intereses, derechos, igualdades y propiedades universales, es decir, por criterios dedicados hasta el momento, solo a los hombres.

Sin embargo ¿Por qué se olvida el carácter patriarcal de la separación en la esfera pública despolitizada y la vida privada? La respuesta recorre las instancias históricas de la división social y cultural de la familia y el hogar y de la familia como el paradigma de lo privado. Locke denunció severamente con respecto al patriarcalismo en la esfera familiar, señalaba que "los maridos eran cabe- zas de familia, pero sus mujeres desempeñaban un papel activo e independiente en procesos de producción". En la actualidad, pese a las medidas para la construcción de una sociedad igualitaria, las esposas siguen subordinadas o dependen de sus maridos, la moralidad y el poder enfrentan un cambio que debe ser generacional.

El sufragio de las mujeres es uno de los ejemplos teóricos y prácticos de la construcción de esta nueva moralidad y poder por parte de las feministas en torno a lo público y privado. Stuart Mill, a raíz de su "The Subjection of Women" impulsaba el sufragio femenino, demostrando que la esfera pública y privada están íntimamente relacionadas con la participación de las mujeres.

Stuart (1970), señala que "La subordinación social de las mujeres era el único vestigio existente de un viejo mundo de pensamiento y práctica que, por lo demás, ha quedado totalmente refutado. La reforma legal debería transformar la familia, que convertiría una escuela de despotismo en una escuela de compasión e igualdad, una verdadera escuela de las virtudes de la libertad y de mantener esa libertad alcanzada" (p. 146).

\section{Género y la virtualidad}

"La mujer, o más exactamente lo que entendemos por mujer (coqueta, frívola, caprichosa, salvaje o sumisa, obediente, cariñosa, etc.), es un producto cultural que se ha construido socialmente".

Simone De Beauvoir

El género, del latín genus, hace referencia a una clase 0 conjunto de determinadas características, que abarca muchas áreas y disciplinas. Empero, en relación a la sexualidad, es un fenómeno que se constituye socioculturalmente, ya que se hace y desarrolla en torno a las relaciones sociales de un determinado ser frente a otro. Se halla afuera del mismo, y va más allá de uno mismo, es una socialidad que no tiene un solo autor, una sola mirada, una solitaria perspectiva.

Socialidad, que se entremezcla con las interacciones políticas y culturales en contextos determinados. El desarrollo del matriarcado, por ejemplo, y consecutivamente, la sistematización del patriarcado, han cimentado y construido históricamente el género. Las viejas modalidades raciales, la exclusión étnica, las diferencias sexuales, el chovinismo especista y las políticas sexistas, no solo han limitado el desarrollo y la construcción del género sino que también la ha desnaturalizado. 
Desnaturalización, que ha separado la parte biológica del ser humano, de su contexto social, económico, cultural y ambiental. En vez de la construcción cultural del género, se vive actualmente la artificialidad del mismo, que se ha desatado principalmente por una especie de Auswitch de identidad cultural de ignorar mucho sobre lo que se es y saber poco de lo que no se debería ser Denegri (2014) tratando de explicar este embrollo refiere que:

Para los biólogos, zoólogos y evolucionistas, el humano es "un miembro del reino animal, del filum de los cordados, del subfilum de los vertebrados, de la clase de los mamíferos, de la subclase de los euterios, del grupo de los placentarios, del orden de los primates, del suborden piticoides, del infraorden de los catarrinos, de la familia de los hominoides, de la subfamilia de los homínidos, del género homo y de la especie sápiens. Sin embargo es más insipiens que sapiens, ignora mucho y sabe poco o simplemente no sabe nada (p. 32).

El género es un subproducto de determinados contextos reales, pero que en la actualidad no solo se limita a desarrollarse dentro de espacios físicos, sino también en el marco de contextos y espacios virtuales. Estos espacios movilizan la interacción del ser humano frente a los demás, en tiempo real facilitando la conexión sencilla y rápida de información, emociones, sentimientos y comportamientos. Se gesta entonces, desde lo virtual, la construcción del ser y por ende del género, que no trasciende los espacios físicos para desarrollarse en espacios virtuales.

Los espacios virtuales, como sistemas abiertos, codifican y entremezclan las diferentes actividades, orientaciones, necesidades y problemáticas que preocupan al ser humano. Desde las redes socio virtuales de Facebook, Tuenti, Twitter o Myspace, hasta los buscadores como Google, Bing, Yahoo, Altavista y otros, están construyendo el género. Esta construcción va desde los procesos de virtualización hasta los de realidización, se entiende así al género como un fenómeno transdisciplinario que se va tecnológicamente construyendo, haciendo, edificando y compartiendo.

\section{Virtualización y realidización del género}

Hace aproximadamente diez mil años, el ser humano aprendió a cultivar la tierra y a surcar sus alimentos, descubrió así, la primera revolución: la revolución agrícola. De fabricantes de hachas, talladores de pie- dras, cazadores nómades y semi nómades, la humanidad pasó a sistematizar el lenguaje y a emplear la lógica en cada una de sus actividades, de la agricultura se pasó a la comunicación, que a mediados del siglo IX se iba sistematizando en razón de los novedosos inventos tecnológicos y del proceso de culturalización de la humanidad.

Esta culturización humana determinaba y determina en la actualidad el género humano, en términos sexuales y también tecnológicos. Desde lo tecnológico, el género, se viene construyendo en el processus de la virtualización y realidización. Entendiendo a la virtualización como el processus de proyectar y crear un ser virtual desde lo real y a la realidización, como el processus de estabilizar un ser real desde lo virtual, todo esto a través de la simulación del futuro.

La virtualización en términos informáticos, es entendida además, como la creación a través de software, de una versión virtual de algún recurso tecnológico o característica humana. Este proceso crea una abstracción del ser real, de sus capacidades, habilidades, destrezas e inteligencias, y las deposita en algunos espacios virtuales. La creación de perfiles en Twitter o Myspace, los likes y comentarios en Facebook o Tuenti, la publicación de videos en Youtube, o el seguimiento a diversas informaciones en Google, Bing, Yahoo 0 Altavista, son una muestra de la virtualización de la humanidad y por ende del género que se va construyendo en ella.

La realidización, en cambio, es entendida como el processus de creación física de algún recurso tecnológico 0 característica humana virtualizada. Es decir, es el proceso mediante el cual, el ser virtual crea una simulación de sí mismo para estabilizarlo en un contexto físico determinado. La creación de avatares en el software Second Life -segunda vida-, es un claro ejemplo de realidización del género, en aquel espacio virtual los residentes -usuarios- crean sus avatares personalizados, para explorar mundos virtuales, participar de diversas actividades, ejercer el comercio virtual y ofrecer servicios múltiples a otros residentes.

El paso de la virtualización a la realidización, se moviliza gracias a la simulación del futuro. Simular el futuro significa proyectar 0 aproximar un determinado hecho o fenómeno desde la mente 0 algún espacio virtual hacia un contexto físico. Einstein pasaba la mayor parte de su tiempo pensando y repensando, mediante experimentos mentales, se encontraba constantemente haciendo complejas simulaciones del futuro en su cabeza, de esta manera su mente se constituía en su laboratorio virtual. 
Laboratorio virtual en el que se construye el género y otras características de la humanidad a fines del siglo XX e inicios del siglo XXI. Estos processus hominum contribuyen a la estabilización del género en contextos tecnológicos cambiantes y avanzados, sin olvidar la raíz, la cultura, los rasgos sociales económicos y ambientales, es posible interconectar nuevos mundos, nuevas culturas y novedosas formas de ver la vida. Como concluye Kurzweil (2008) "nuestro destino es despertar al universo para luego decidir inteligentemente cuál es su futuro inbuyéndole de inteligencia humana en su forma no biológica" (p. 284).

\section{REFERENCIAS BIBLIOGRÁFICAS}

Asimov, I. (1953). El fin de mi infancia. México: Trillas.

Aurel, A. (2013) La cibernética y lo humano. Estados Unidos de Norteamérica: Eair List.

Bostrom, L. (1989), Human enhancement, cit., $277-$ 289.

Brown, D. (2013) Inferno. España: Editorial Planeta.

Butler, J. (2007). El género en disputa. Barcelona: Paidós.

Cerrón, W. y Orosco J. (2014) Valores virtuales, (Tesis pre grado). Universidad Nacional del Centro del Perú, Unidad de Posgrado. Huancayo, Perú.

Denegri, A. (2014). Poliantea. Lima: Fondo Editorial de la UIGV.

Heiddegger, M. (1947). Carta sobre el humanismo. Madrid: Taurus Ediciones.

Hernández Gómez, J. (2008). Episteme de la inteligencia. Revista de inteligencia.
Kaku, M. (2014) El futuro de nuestra mente, el reto científico para entender, mejorar y fortalecer nuestra mente. (1ra ed.). Barcelona, España: Penguin Random House Grupo Editorial S.A.

Kurzweil, R. (2008) Cómo crear una mente, el secreto del pensamiento humano. (1ra ed.). Berlín: Lola Books.

Martel, C. (2013) Filosofía y virtualidad. Valparaíso, Argentina: Universidad de Valparaíso.

Negroponte, N. (2007). Inteligencia digital, una introducción a la noosfera digital. España: Dúplex S.A.

N. Krúpskaya (1956) Selección de artículos y discursos.

Pierre, L. (2007).Cibercultura. Barcelona: Paidós Ibérica.

Patrón, P. (2007). Ética y género. Lima, Perú: Ediciones Atenea E.I.R.L.

Roncoroni, U. (2009) Arte y estética digital. Estudios y críticas desde Latinoamericana. Lima, Perú: San Martín de Porres.

Siemens, G. (2009). Conectivismo, una propuesta pedagógica. México: GuadaS.A.

Stuart, J. (1970). The Subjection of Women. Chicago: University of Chicago Press.

Viñas, M. (2010) Los prolegómenos del bumanismo digital. España: Debolsillo.

Wark, M. (2013). Manifiesto Hacker. Austria: Porsl.

Wiener, N. (1989) Cibernética presente y futuro. Madrid, España: Cartago. 